\title{
A busca por diálogos entre uma-Lulik e escola e o tensionamento com o modo de vida dominante: $\mathrm{O}$ exemplo de Timor-Leste ${ }^{1}$
}

\section{The search for dialogues between and-Lulik and school and the tensioning with the dominant life mode: Timor-Leste's example}

ROSIETE COSTA DE SOUSA

Doutoranda em Educação da

Universidade Federal da Bahia (UFBA) rosietesousa@gmail.com

ROBERTO SIDNEI MACEDO

Professor Titular da Faculdade de Educação da

Universidade Federal da Bahia (UFBA)

rsmacedo@outlook.com.br

VICENTE PAULINO

Doutor em Ciências da Cultura - Professor da Universidade Nacional Timor Lorosa'e (UNTL) vicentepaulino123@gmail.com

\section{RESUMO}

Este artigo, produzido no contexto de uma pesquisa de doutorado em Educação que investiga currículo e formação no Timor-Leste, perguntando sobre o diálogo possível entre escola e uma-lulik (instituição ancestral timorense), visa, ao tomar como referência a uma-lulik, tecer algumas considerações que levam em conta a necessidade e urgência de tensionamento e alteração do modelo de sociedade hegemônico, que tem revelado cada vez mais a sua enorme incapacidade de cuidar da vida, bem como mostrar teorias e conceitos com os quais a escola pode operar no sentido de se aproximar mais da experiência da uma-lulik. Como parte da nossa etnopesquisa-formação, uma prática de pesquisa multirreferencial, o texto se configura num conjunto de argumentos que conjugam noções culturais, teorias e conceitos, fazendo entrever o significado do diálogo entre uma-lulik e escola, sua potência pedagógica, cultural e política.

Palavras-chave: Uma-lulik. Currículo. Formação. Teoria Etnoconstitutiva do Currículo. Etnopesquisa.

\begin{abstract}
This article, produced in the context of a doctoral research in Education that investigates curriculum and formation in Timor-Leste, asking about the possible dialogue between a school and the uma-lulik (Timorese ancestral institution), aims, by taking the uma-lulik as a reference, to weave some considerations that take into account the need and urgency of tensioning and altering the hegemonic model of society that has increasingly revealed its enormous inability to take care of life, as well as showing theories and concepts with which the school can operate in order to approach of the experience of the uma-lulik. As part of our ethno-research-training, a multi-referential research practice, the text is configured in a set of arguments that combine cultural notions, theories and
\end{abstract}

\footnotetext{
${ }^{1}$ Artigo submetido em 20/08/2020 e aprovado em 10/03/2021.
} 
Rev. Interd. em Cult. e Soc. (RICS), São Luís, v. 7, n. 1, p. 108- 126, jan./jun. 2021

ISSN eletrônico: 2447-6498

concepts, showing the meaning of the dialogue between uma-lulik and school and its pedagogical, cultural and political potency.

Keywords: Uma-lulik. Curriculum. Formation. Curriculum Ethno-constitutive Theory. Ethnosearch.

“Amada Mãe Terra, que é quem eu sou Se eu, a minha família, os meus parentes e antepassados Te maltratamos com pensamentos, palavras, fatos e ações Desde o início de nossa criação até o presente

Eu peço o teu perdão.” (Hooponopono)

\section{INTRODUÇÃO}

Iniciamos com uma narrativa da primeira autora.

No momento em que estou escrevendo este texto, tenho uma experiência de grande identificação com uma árvore que é cortada na frente da casa onde vivo agora, a qual, quando aqui cheguei, já havia sido derrubada, porque o encanamento do esgoto teria sido estourado pelas suas raízes. Quando cheguei, ela estava derrubada e sem verde, parecia ter já morrido. Pouco tempo depois, talvez uns dois meses, vi seus rebentos surgirem e ir crescendo. Eu experimentava a alegria de tê-la ali se renovando, enchendo tudo à frente da casa de verde e de vida, porque, além dela, ali chegavam pássaros, macaquinhos, outros bichos, os gatos brincavam e descansavam em parte do seu tronco e ramos, ainda que caídos, mas que já estavam cobertos pelos novos ramos que cresciam mais e mais a cada dia que se passava e já podiam sustentar muitos deles.

A casa onde moro é alugada. Ouvi sua dona dando ordens a um trabalhador para que fizesse aquela árvore desaparecer dali, porque ela não servia para nada, se produzisse frutos para comer não estava assim, ela somente dava prejuízo, já tinha arrebentado o cano do esgoto e estava ameaçando a estrutura da construção ali erguida. Eu mal podia acreditar no que estava ouvindo. No outro dia, o trabalhador com suas ferramentas de trabalho (o facão, o machado) foi cortando tudo. Nenhum ritual foi feito. Nenhum pedido de licença. Os donos da propriedade por si sós decidiram e se sentiam autorizados a derrubar, cortar, matar. Aqui a natureza não é sagrada, virou propriedade apenas.

Perguntas me saltaram à mente: Por que não buscar outra solução? Por que não procurar desviar o encanamento do esgoto? Por que não quebrar um pedaço do terreno coberto pelo concreto para dar espaço para a árvore? A solução que parece ter sido a mais fácil foi derrubar e, agora, que ela havia conseguido viver novamente, a ordem era acabar de vez com ela. O que aconteceu conosco? Por que nos tornamos tão separados dos outros seres 
Rev. Interd. em Cult. e Soc. (RICS), São Luís, v. 7, n. 1, p. 108- 126, jan./jun. 2021

ISSN eletrônico: 2447-6498

que também vivem? Por que nos tornamos tão indiferentes a eles? Por que construir encostado ao tronco da árvore? Por que não respeitamos o seu espaço? Por que somos tão invasivos e destruidores da vida que nos cerca? Aqui é um conjunto de casas que foram feitas para alugar. O objetivo é o lucro. É isso, para se obter lucro, ter mais dinheiro, vai-se passando por cima do que estiver pela frente, passa-se por cima da vida, destruindo-a sem - é o que muitas vezes parece - sentir qualquer coisa por isso.

Penso na dor da árvore, senti muito, fiquei muito triste e sei que todos os outros bichos que conviviam com ela também ficaram. Assistimos à violência à vida sem que nada pudéssemos ou nos permitíssemos fazer para impedi-la. Apenas sentimos a dor de tê-la perdido.

Não penso que as pessoas são más, apenas penso e sinto que precisamos reaprender a ligação com a natureza, o respeito e reverência a ela. Vejo que muitas vezes as pessoas não têm qualquer consciência do mal que estão fazendo, não sabem que estão ferindo, machucando os outros seres. Parece que estamos completamente ignorantes neste sentido.

Há não muito tempo atrás, eu mesma me comportei de um modo bastante insensível com uma adolescente de 18 anos de idade. Estávamos eu, ela e sua mãe conversando depois de jantarmos. A adolescente nos contou uma experiência sua de sofrimento ao ver uma galinha que parecia estar com fome e machucada, certamente caíra de um daqueles caminhões que as levam para o abate. Ela desejou fazer algo, quis muito ajudar aquele ser a se recuperar e ficar bem, mas o que podia fazer? Morava num apartamento com sua mãe e mais uma pessoa que alugava um dos quartos. Não tinha espaço para cuidar da galinha. Já tinha vivido uma experiência difícil quando cuidou de um passarinho ferido lá. Mas ela ainda tentou fazer algo, falando para sua mãe com a esperança de que pudesse voltar lá no outro dia e pegar a galinha para cuidar. Era visível seu sofrimento enorme com a situação. Eu simplesmente, naquele momento, achei aquilo um exagero, porque "era fato" que estas galinhas são criadas para ser comercializadas, consumidas e não via muito sentido em se sofrer por causa de uma delas. Aí estava eu diante de minha insensibilidade e indiferença com a vida de um outro ser.

A experiência agora vivida com a árvore me fez recordar aquele momento compartilhado com a adolescente que sofria por causa da galinha ferida, machucada, produto de um modo de vida centrado no mercado e numa lógica de descarte da vida. Quero dizer com isso que nos formamos num modelo de sociedade que não deixa muita alternativa, afastamo-nos, pelo que aprendemos deste/neste modelo, da natureza que, inclusive, somos primordialmente. E já não nos restam dúvidas de que isso tem nos adoecido muito.

Estou em casa há cinco meses, vivendo sob a ameaça de um vírus. 
Rev. Interd. em Cult. e Soc. (RICS), São Luís, v. 7, n. 1, p. 108- 126, jan./jun. 2021

ISSN eletrônico: 2447-6498

Importante termos em conta o que nos diz a física, ecofeminista e ativista ambiental Vandana Shiva, escrevendo sobre a pandemia do coronavírus: "esta pandemia não é um desastre natural, assim como os fenômenos climáticos não são. As epidemias emergentes, assim como a mudança climática, são antropogênicas, ou seja, causadas pelas atividades humanas."2

Shiva (2020, p. 2) menciona ainda que

Ao longo dos últimos 50 anos, apareceram 300 novos patógenos. Está escancaradamente documentado que $70 \%$ dos patógenos que afetam o ser humano, entre os quais estão o HIV, o ebola, a gripe, a síndrome respiratória do Oriente Médio (MERS, na sigla em inglês) e a síndrome respiratória aguda grave (SARS, na sigla em inglês) surgem quando os ecossistemas florestais são invadidos e os vírus se transferem de animais para pessoas. Quando se amontoam animais em fazendas industriais para maximizar os lucros, afloram novas doenças como a gripe suína e a aviária.

Num contexto de globalização, o mundo inteiro se viu muito rapidamente ameaçado e sofrendo a ação do novo coronavírus. A ciência, o Estado, a Organização Mundial da Saúde não tinham/têm uma resposta tão rápida para dar conta de conter o vírus. Temos já mais de vinte milhões de casos da doença causada pelo coronavírus (COVID-19) confirmados e o número de mortes já chega a mais de setecentos mil. ${ }^{3}$. Convivemos com a incerteza da continuidade da vida que já é, claro, naturalmente incerta, mas que neste momento se tornou muito mais intensa e, quando não nos paralisa, põe-nos, e é importante que nos ponha mesmo, reflexivos sobre que mundo é este em que estamos vivendo. Podemos reconhecer que esta pandemia marca a história do mundo, como nos diz Boaventura de Sousa Santos $(2020)^{4}$, que a identifica como o marco que define o início do século XXI.

A pandemia expõe a consequência da nossa violência em relação à natureza, como também Leonardo Boff (2017) vem advertindo: “nossa presença na Terra é agressiva, movemos uma guerra total à Gaia, atacando-a em todas as frentes. A consequência direta é que a Terra adoece. Adoecemos a terra e a terra nos adoece". 5 É sabido, e já foi indicado neste texto com a citação de Shiva, o relatório da ONU para a prevenção de outras pandemias ${ }^{6}$

\footnotetext{
${ }^{2}$ Artigo publicado por El Salto, 11-04-2020. Disponível em http://www.ihu.unisinos.br/598043. Acesso em 15 de abril de 2020.

${ }^{3}$ De acordo com dados da OMS em 20 de agosto de 2020. Disponível em: https://www.paho.org/pt/covid19. Acesso em 20 de agosto de 2020.

4 No vídeo "Desafios da pandemia para a sociedade, para a ciência e para o CES. Disponível em https://youtu.be/HzNZg9DP010. Acesso em 17 de junho de 2020.

$\begin{array}{lllllll}\text { Artigo de Leonardo Boff publicado em } & \text { 28/10/2017. } & \text { Disponível em }\end{array}$ https://educezimbra.wordpress.com/2017/10/28. Acesso em 17 de abril de 2020.

${ }^{6}$ Preventing the next pandemic: Zoonotic diseases and how to break the chain of transmission. A Scientific Assessment with Key Messages for Policy-Makers. A Special Volume of UNEP's Frontiers Report Series.
} 
Rev. Interd. em Cult. e Soc. (RICS), São Luís, v. 7, n. 1, p. 108- 126, jan./jun. 2021

ISSN eletrônico: 2447-6498

reafirma isto, que o que provoca as pandemias também é o mesmo que provoca a mudança climática e a perda de biodiversidade. Escreve Inger Andersen no relatório mencionado:

At the heart of our response to zoonoses and the other challenges humanity faces should be the simple idea that the health of humanity depends on the health of the planet and the health of other species. If humanity gives nature a chance to breathe, it will be our greatest ally as we seek to build a fairer, greener and safer world for everyone. (2020, p. 4).

Como a humanidade vai poder dar à natureza a chance de respirar?

Santos (2020) aponta como um dos cenários possíveis, a partir da pandemia, aquele que se desenrola desta oportunidade de pensarmos em alternativas a esse modelo civilizacional em que nos encontramos, de pensarmos em termos culturais profundos.

É neste cenário que vemos na investigação do diálogo possível entre escola e umalulik, no campo de currículo e formação, a possibilidade de reconhecermos elementos para reflexões em torno de nossas existências e modos de vida desenvolvidos e em desenvolvimento e suas relações com a Natureza, que possam nos embalar, reanimar, vivificar na busca e construção de alternativas.

Como parte de uma etnopesquisa-formação ${ }^{7}$, este trabalho se insere, pois, numa proposta de pesquisa e intervenção, onde o saber/ a construção do conhecimento que se pleiteia constitui-se numa "emergência generativa e acionalista de uma hermenêutica-com que toma como cenário significativo os pertencimentos, as ações afirmativas e suas referências' (MACEDO, 2012, p. 41).

Traremos, a seguir, uma discussão em torno dos significados da $u m a-$ lulik $^{8}$ instituição ancestral timorense, tendo como referências trabalhos de descrições etnográficas de Timor-Leste e/ou da região do sudeste asiático e como um pressuposto básico a ideia de que a uma-lulik nos permite ver a cultura nos termos em que a concebeu Raymond Williams, como "a whole way of life" (apud PAULINO, 2012, p. 11). Na continuação, articularemos abordagens, teorias, noções e conceitos com que a escola pode operar no sentido de se aproximar mais da experiência da uma-lulik.

United Nations Environment Programme. Publicação de julho de 2020. Disponível em: https://reliefweb.int/sites/reliefweb.int/files/resources/ZP.pdf. Acesso em 13 de julho de 2020.

${ }^{7}$ Ver Macedo (2006; 2012).

${ }^{8}$ Tradução do tétum para o português: uma (casa), lulik (sagrada) = casa sagrada. 
Rev. Interd. em Cult. e Soc. (RICS), São Luís, v. 7, n. 1, p. 108- 126, jan./jun. 2021

ISSN eletrônico: 2447-6498

\section{UMA-LULIK: "A WHOLE WAY OF LIFE"}

Para que fique clara a visão de uma-lulik de que partimos, mostraremos abaixo o esquema estrutural da uma-lulik apresentado por Paulino (2012), o qual parte da formulação feita por Sousa (2009), a partir da função estrutural do Adat (Paulino (2012, p. 71).

De acordo com Sousa, adat

refers to the recurrent term used by Timorese people to designate the belief and practice of religious cult concerning their ancestors, their sacred houses and rituals, as well as people who perform or have a task in this system. In certain contexts, adat is equated to tradisaun or costume, tradition and custom; the old Portuguese term estilu or cultura is also used as others say that their practices are "ita nia cultura, ita nia tradisaun" - our culture, our tradition. (SOUSA, 2009, p. 105).

Paulino (2012, p. 53) esclarece que adat é um termo referido na língua indonésia que teria o mesmo significado que o termo lisan, que é "uma combinação de crenças, tradições e costumes do povo timorense".

Devemos compreender a Lisan, ou adat, como o berço de toda a evolução das atividades sociais que engloba o ciclo ecológico, o ciclo econômico, as estruturas sociais e ideológicas. De fato, está enraizada na contemporaneidade da sociedade timorense. O respeito pela lisan, ou adat, é um sentimento de orgulho nacional para o povo timorense. Lisan, particularmente, pode expressar-se noutros termos, consoante as línguas dos grupos étnicos timorenses. (PAULINO, 2012, p. 53).

Vale ainda destacar o que menciona Sousa (2009, p. 111) "lisan in Mambae is kin to the term lulik in Tetum". E é o termo uma-lulik que Paulino apresenta para designar a matriz do modo de vida dos timorenses no esquema abaixo. 
Rev. Interd. em Cult. e Soc. (RICS), São Luís, v. 7, n. 1, p. 108- 126, jan./jun. 2021

Figura 1 - A função da uma-lulik

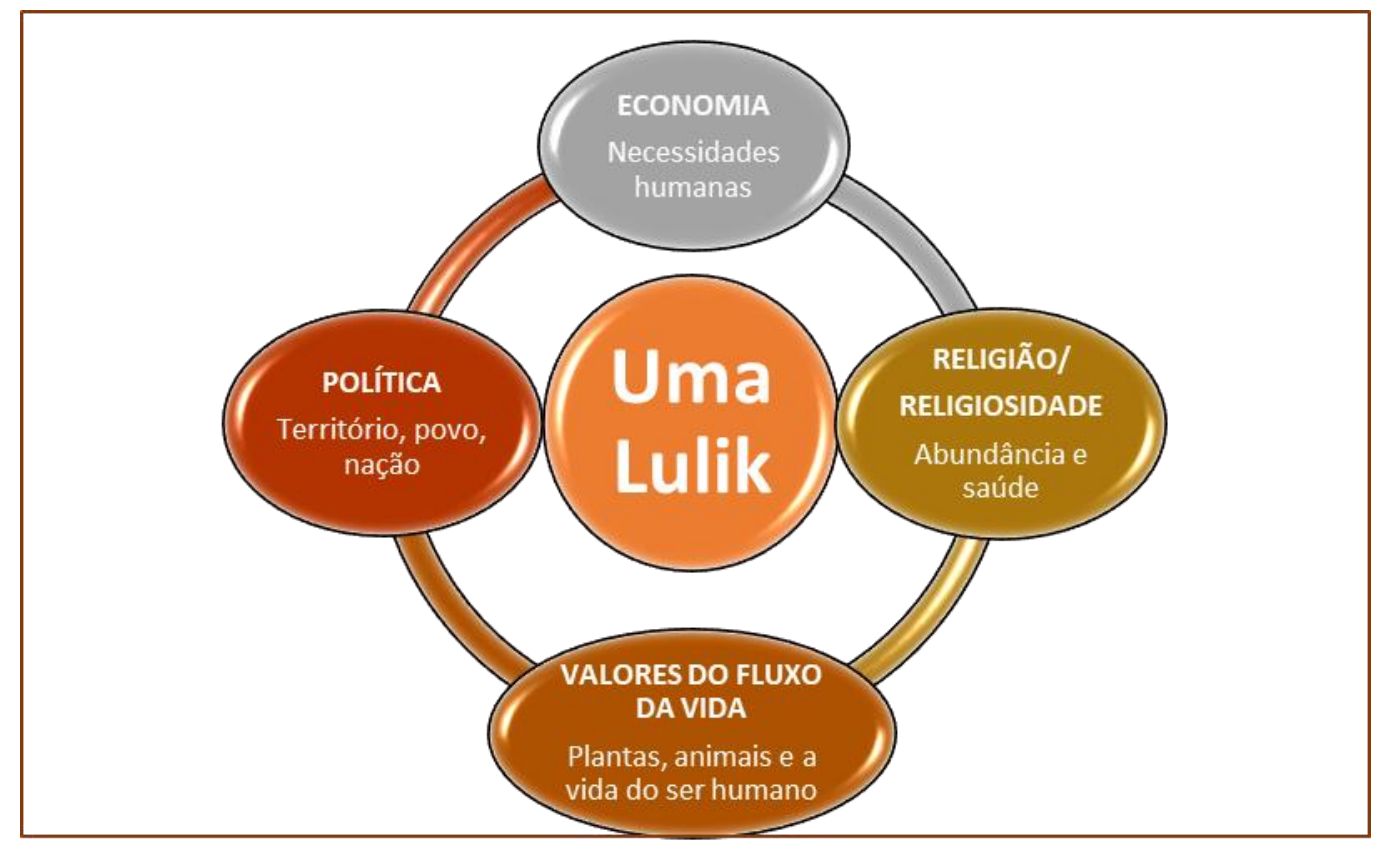

Fonte: PAULINO, 2012, p. 71.

Estamos diante de um esquema que mostra a uma-lulik integrando diferentes elementos constitutivos de um modo de vida, a ela estão inter-relacionados todos os seres e todas as atividades que fazem parte da vida vivida no território de seu domínio, o que nos permite pensá-la como "a whole way of life". De acordo com Williams (apud AZEVEDO, 2017), “[...] se tomarmos qualquer uma dessas atividades, podemos ver o quanto das outras se encontra refletido nela, de várias maneiras, de acordo com a natureza da organização global". Trata-se, pois, "de estudar todas as atividades e suas inter-relações, sem qualquer concessão de prioridade a qualquer uma que possamos escolher para abstrair" (WILLIAMS apud AZEVEDO, 2017, p. 214), o que implica no uso do termo cultura por este autor designando todo um modo de vida, que envolve tanto sua produção material como simbólica e, fundamentalmente, as relações entre elas. Esclarece Williams:

A ordem social e política que mantém um mercado capitalista, como as lutas políticas que a criam, é necessariamente uma produção material. De castelos a palácios, de igrejas a prisões, de escolas a locais de trabalho; de armas de guerra a uma imprensa controlada: qualquer classe dominante, de formas variadas embora sempre materialmente, produz uma ordem social e política. Estas nunca são atividades superestruturais. Elas são a produção material necessária dentro da qual um modo de produção em aparência subsistente por si mesmo pode ser exercido. A complexidade desse processo é especialmente notável em sociedades capitalistas avançadas, onde é totalmente impensável isolar 'produção' e 'indústria' da produção material comparável de 'defesa', 'lei e ordem', 'bem-estar', 'entretenimento' e 'opinião pública'. Ao falhar em compreender o caráter material da produção 
Rev. Interd. em Cult. e Soc. (RICS), São Luís, v. 7, n. 1, p. 108- 126, jan./jun. 2021

ISSN eletrônico: 2447-6498

de uma ordem política e social, esse materialismo especializado (e burguês) falha também, porém ainda mais conspicuamente, em entender o caráter material da produção de uma ordem cultural. (WILLIAMS apud AZEVEDO, 2017, p. 220).

Interessa-nos trazer aqui um pouco da arquitetura da casa nomeada uma-lulik. Vamos nos deter em duas das peças que compõem o telhado - o diu (chifre) ou bou-diu (avô + chifre) e a ai-manuk-rua (árvore + duas aves), com base na descrição da Casa Turi-Sai ${ }^{9}$ feita por Barros (1975).

Figura 2 - Telhado da Casa Hulcai

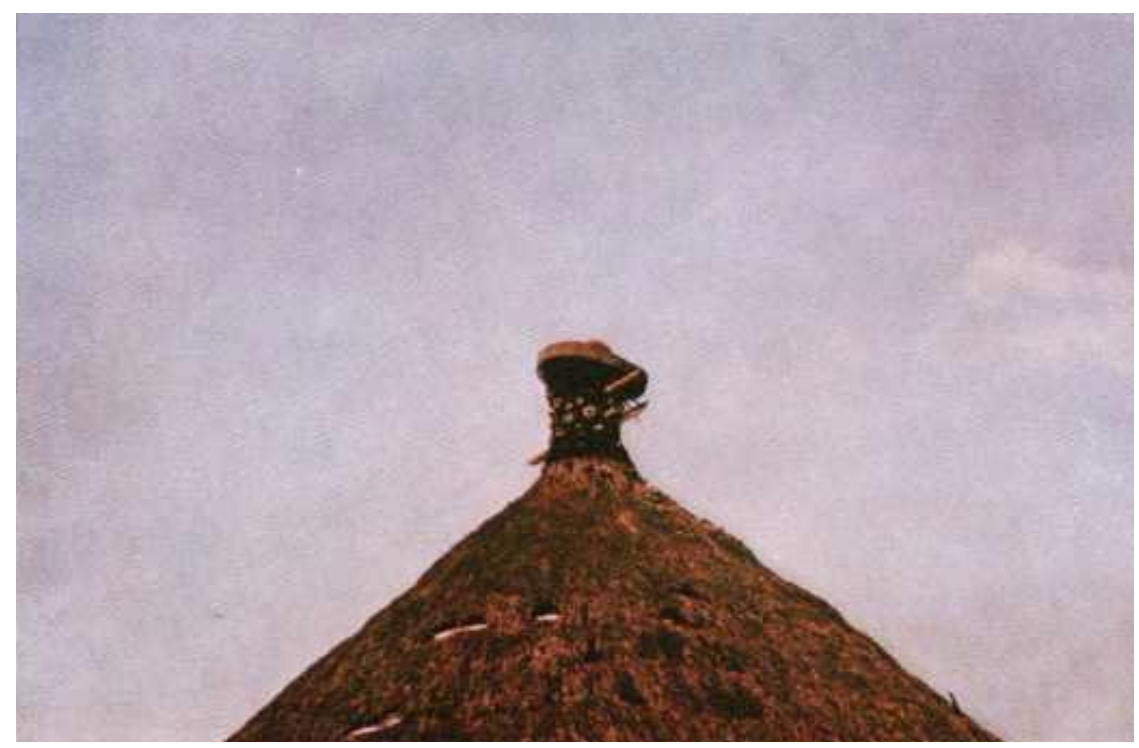

Fonte: BARROS, 1975, p. 36.

Segundo Barros, a presença da ai-manuk-rua ${ }^{10}$ formando um todo com a cobertura cônica da casa simularia a árvore que, na cosmologia timorense, como de muitos outros povos orientais, afirma o autor, tem todo um simbolismo, com sentidos que podem facilmente ser associados ao que observa Campbell:

\footnotetext{
9 "Barros estudou as relações entre a classificação simbólica e a vida social da dinastia de Turi-Sai, cuja origem mais próxima é da povoação Manu-Sae-Mau-Ili, situada no monte Keo. A referida dinastia espalha-se em pequenos núcleos nas zonas de Hatubuilico e de Manufahi, como se pode notar na arquitetura e ordenamento das casas" (PAULINO, 2012, p. 85). "Das duas casas de Turi-Sai a principal e a maior é a Fad-Culau (casa+casuarina), a casa umane (naen-ru-ni fada, isto é, casa dos dois tios ou sogros), que dista da estrada apenas uns escassos metros. A outra, mais recolhida numa prega da montanha, é Fad"-Hulcai (casa+lua), a casa fetosá (man-heu ni fada, isto é, casa do genro). Os nomes de Culau e Hulcai, atribuídos, respectivamente, à casa umane e à casa fetosá de Turi-Sai, são patronímicos. O primeiro refere-se a um antepassado varão da metade umane, $\mathrm{e}$ o segundo, a um antepassado fêmea da metade fetosá" (BARROS, 1975, p. 1).

${ }^{10}$ Esta peça consiste numa haste cilíndrica, de cerca $8 \mathrm{~cm}$ de diâmetro, que a pouco mais de $1 \mathrm{~m}$ do seu comprimento forqueia e atravessa o telhado, projetando, por cima do centro apical do cone, as suas duas ramificações (BARROS, 1975, p. 18).
} 
Rev. Interd. em Cult. e Soc. (RICS), São Luís, v. 7, n. 1, p. 108- 126, jan./jun. 2021

ISSN eletrônico: 2447-6498

We note, furthermore, the surprising detail of the central pole, which in the higher Mythologies becomes interpreted as the world-uniting and supporting Cosmic Tree, World Mountain, axis mundi or sacred sanctuary, to which both the social order and the meditations of the individual are to be directed. (CAMPBELL apud BARROS, 1975, p. 20).

A peça diu ou bou-diu, que tem a forma de crescente ou chifre de búfalo, é utilizada para segurar e travar a haste da ai-manuk-rua. De acordo com Barros (1975), o diu (chifre) ou bou-diu (avô + chifre) é um símbolo presente em toda a Indonésia e até em civilizações mais antigas (1975, p. 25). O diu simbolizaria a força, o poder. Teria a mesma representação o caibauk, que é usado como enfeite da cabeça.

Nalgumas regiões de Timor, por exemplo em Suai, este emblema da cabeça é composto por dois caibauks sobrepostos um ao outro e unidos entre si por uma haste comum. Cinatti (1954) reconhece nesta forma composta do caibauk o emblema da árvore da vida. Também se encontram, por vezes, em Timor, caibauks de ouro ostentando, nos bicos, dois discos do mesmo metal, como símbolos do Sol e da Lua. Estes emblemas recordam-nos certas representações da árvore da vida dos Ngaju e de outros povos, como os povos altaicos, em que o símbolo arbóreo se apresenta ladeado pelo Sol e pela Lua. (BARROS, 1975, p. 26)

O diu também está relacionado com o avô, os antepassados, o que estaria, inclusive, sinalizado no próprio vocábulo bou-diu (avô + chifre), observa Barros (1975, p. 27). A árvore - a hali (gondoeiro) costuma indicar locais sagrados - e o chifre teriam um significado associado aos antepassados. 
Rev. Interd. em Cult. e Soc. (RICS), São Luís, v. 7, n. 1, p. 108- 126, jan./jun. 2021

ISSN eletrônico: 2447-6498

Figura 3 - Hali

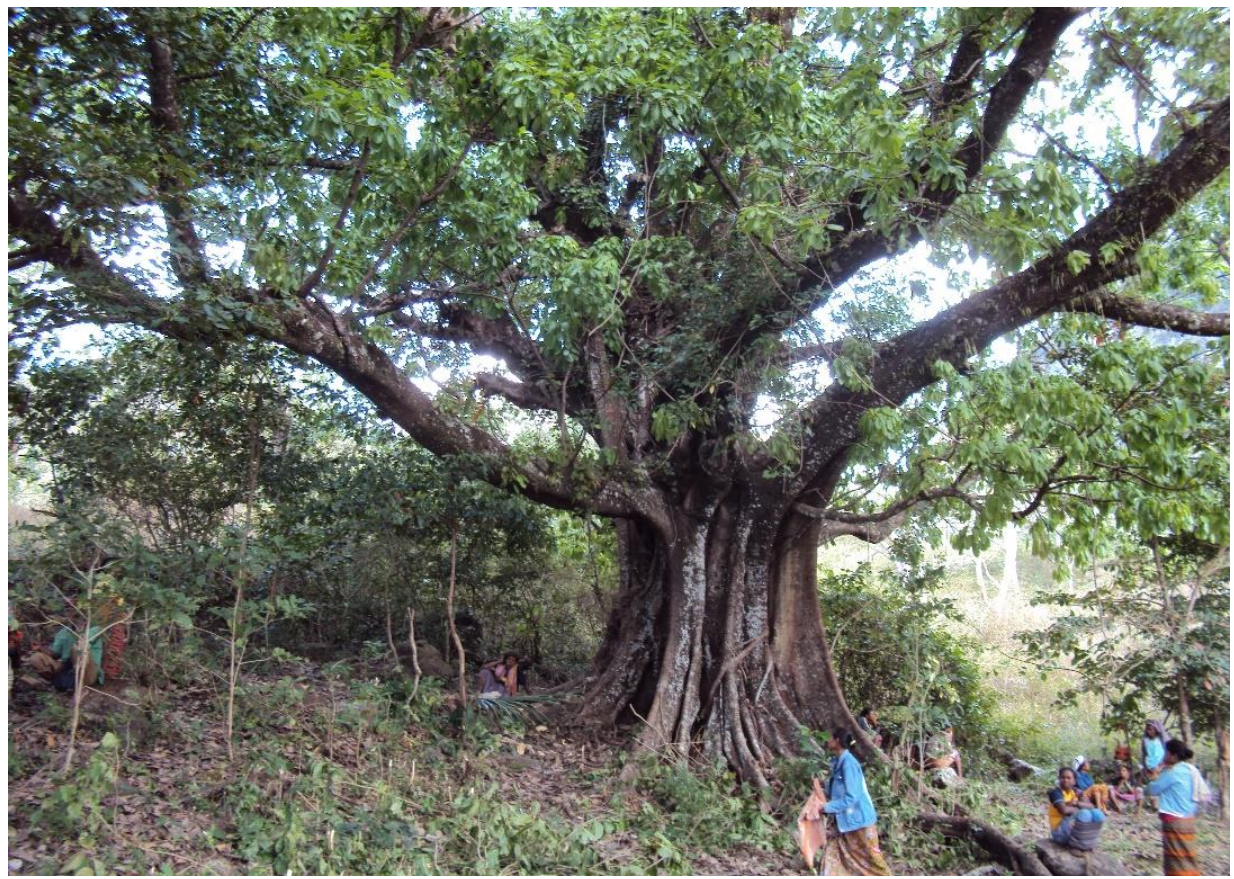

Fonte: Compilação da 1a autora, $2010 .^{11}$

Em Turi-Sai, encontra-se a árvore sagrada Hali Beremau. Beremau era o nome de um antepassado, quem, segundo seus descendentes, teria plantado a mencionada hali, diz Barros (1975, p. 30).

Para sublinhar a relação da uma-lulik com os antepassados, indicamos, a seguir, a fala de dois professores formadores timorenses no Observatório Etnoformador em Timor-Leste ${ }^{12}$ ObEtno-TL (SOUSA, 2019, p. 117).

Que uma-lulik... e também casa sagrada, a função é realizar as atividades como o sr. Chico falou... usando, intervindo com os utensílios que os nossos antepassados deixaram aí, que representam também a existência dos passados e para fazer isso, para realizar isso é... como prof. Manuel já explicou, por meio dos sacrifícios, dos rituais, das cerimônias tradicionais. Por meio de cerimônias tem uma ligação entre terrestres e supernatural, sobrenatural... uma comunicação. É uma linguagem simbólica tradicional. Só os sacerdotes ${ }^{13}$ aí que sabem. Ele que liga nós aos nossos antepassados. Os timorenses têm mais relação íntima com os seus pais, seus avós, que já morreram. Ele tem relação muito íntima, é mais próximo, quase que ele

\footnotetext{
${ }^{11}$ Registro feito pela primeira autora durante acompanhamento do início do processo de reconstrução da UmaLulik Oholau, em Kailaku, Bobonaro, Timor-Leste, em julho de 2010.

${ }^{12} \mathrm{O}$ observatório etnoformador é o principal dispositivo metodológico-formativo da nossa etnopesquisaformação em andamento no Programa de Pós-Graduação em Educação da Universidade Federal da Bahia, de "perspectiva localista, relacional, irrestritamente dialógica e indexicalizada de tratar com questões de currículo e pautas formativas, em geral secularmente coladas às decisões exterodeterminantes, às recomendações academicistas" (MACEDO, 2013, p. 148). O ObEtno-TL apontou a uma-lulik como uma referência para uma abordagem do conhecimento e da formação que reconhece e valoriza as experiências antropossocioculturais vividas no território timorense. A experiência do grupo, de 2013 a 2015, foi analisada na dissertação de mestrado da primeira autora (UFSC, 2019).

${ }^{13}$ O prof. João está a se referir ao sacerdote tradicional, o lulik nain, o lianain.
} 
Rev. Interd. em Cult. e Soc. (RICS), São Luís, v. 7, n. 1, p. 108- 126, jan./jun. 2021

ISSN eletrônico: 2447-6498

considera ainda vive, vive na existência de seus... patrimônios... prato, ou um surik $^{14}$ ou um tais $^{15}$, em qualquer utensílio que eles usavam, ou uma matéria de guerra. Aí eles... deixaram aí... então eles... os timores julgam que ele, o espírito dele, a sua existência ainda está aqui, ele não vai nos deixar. [...] Eles nos deixaram, somos descendentes deles, que nós não esquecemos. Somos netos, filhos deles ou bisnetos deles. É... E depois... e outra coisa. Nós agradecemos porque eles deixaram as várzeas, as hortas... muitas coisas pra nós, pra agora utilizarmos e vivermos. E também que deixaram esses procedimentos. São coisas que nós podemos agradecer para os nossos antepassados. [...] para o bem da saúde, da educação, de várias formas que a gente pede para dar uma proteção porque ele nos conhece, ele conhece bem. Ele não é um abstrato, mas é ele que já viveu conosco, que ainda permanece no nosso sentimento, todos os nossos sentidos, ele nos sabe bem [...] (Prof. João, 19 de março de 2014).

[...] segundo a crença timorense, os timorenses não podem viver sozinhos aqui no mundo real sem ser acompanhado pelos antepassados que já morreram, mas segundo a fé timorense os mortos ainda vivem. [...] os timorenses não podem viver sem ter vínculo com o grupo familiar, principalmente centrado na casa tradicional. Está aqui um ponto principal da tradição timorense que hoje em dia mantendo... continua a manter, principalmente, as pessoas que vivem no interior... é uma coisa interessante. (Prof. Manuel, 19 de março de 2014).

Assim, a uma-lulik define uma cosmologia e "personifica" a ancestralidade do grupo que representa, conforme escreve James Fox a respeito das casas austronésias:

The house itself, and not just the objects and elements within it, can also constitute a ritually ordered structure. As such, this order can be conceived of as a representation of a cosmological order. In some Austronesian societies, the house is regarded as the ancestral 'embodiment' of the group it represents. As either representation or embodiment, the house may become a centre - a combination of theatre and temple - for the performance of the ceremonies of social life. (FOX apud PAULINO, 2012, p. 30).

Uma ordem social e política é, pois, uma produção material. A cosmologia é materializada. Se a uma-lulik passa a ter somente um papel figurante na ordem social e política que o Estado representa, o que acontece com a produção material (o que não está separado do simbólico) da vida em Timor-Leste? Temos como pressuposto a ideia de que a uma-lulik nos permite ver a cultura nos termos em que a concebeu Raymond Williams, como "a whole way of life" (apud PAULINO, 2012, p. 11) e consideramos também que a uma-lulik define uma cosmologia e "personifica" a ancestralidade do grupo que representa (FOX apud PAULINO, 2012, p. 30). E é nesse sentido que defendemos que a educação escolar precisa tomar a uma-lulik como referência em termos fundacionais, acreditando também que é este papel que ela precisa ter na construção do estado timorense, se não quisermos nos render aos

\footnotetext{
${ }^{14}$ Espada.

${ }^{15}$ Tecido tradicional timorense.
} 
Rev. Interd. em Cult. e Soc. (RICS), São Luís, v. 7, n. 1, p. 108- 126, jan./jun. 2021

ISSN eletrônico: 2447-6498

ditames modernizantes do modo de vida capitalista e deixar que a uma-lulik figure apenas como uma representação da vida no passado.

\section{ABORDAGENS, TEORIAS E CONCEITOS NA CRIAÇÃO DE DIÁLOGOS ENTRE ESCOLA E UMA-LULIK}

Figura 4 - Educação escolar na interação com as demais atividades e cosmologia da Uma-Lulik

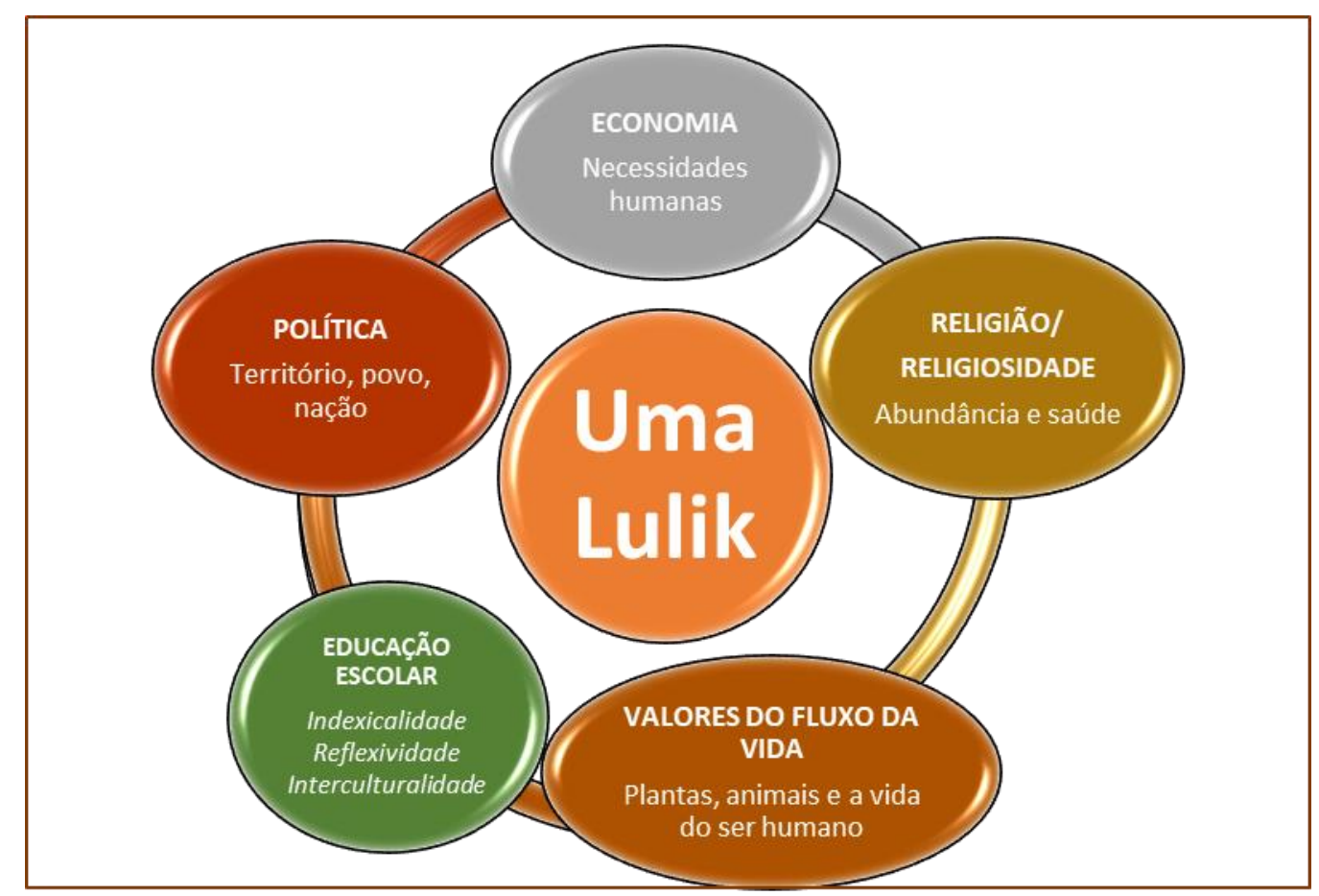

Fonte: Os autores, $2020 .^{16}$

Tomamos como base teórico-epistemológica no campo do currículo e formação a Teoria Etnoconstitutiva de Currículo (TEEC), elaborada por Macedo (2016), como uma alternativa na busca por evitar, ou mesmo, lutar contra o desperdício das experiências, tornadas invisíveis tal como os seus autores no Sul global (SANTOS, 2010, p. 34). Macedo afirma que o trabalho com a mediação intercrítica, um conceito-dispositivo da TEEC criado a partir das elaborações de Henri Atlan, epistemólogo francês, ao considerar as várias racionalidades e múltiplas maneiras de se ter razão, permite

alcançar uma perspectiva fecunda para evitarmos, pelos processos interculturais vividos no currículo, a colonização via destruição das tradições das pessoas que historicamente foram impedidas de afirmar ou mesmo de reconquistar suas subjetividades culturais e têm na escola um locus de pasteurização dos seus saberes e de seus pertencimentos, e portanto, das

\footnotetext{
${ }^{16}$ Elaborado pelos autores a partir da figura 1.
} 
Rev. Interd. em Cult. e Soc. (RICS), São Luís, v. 7, n. 1, p. 108- 126, jan./jun. 2021

ISSN eletrônico: 2447-6498

referências com as quais compreendem o mundo, a vida e com isso aprendem (MACEDO, 2016, p. 138).

Macedo aponta para uma etnoeducação crítica, ou mesmo para um etnocurrículo crítico. O conceito de etnocurrículo, descrito por Macedo (2016, p. 80) como o currículo que se caracteriza pelo trabalho com os etnométodos culturalmente construídos de todas as pessoas implicadas às questões de currículo e formação, percebidas aí como atores curriculantes, é mais um dos conceitos que fundam e sistematizam a TEEC, juntamente com atos de currículo, instituintes culturais da formação e do currículo.

Compreendemos que o que se faz necessário não é a coleta de dados sobre a cultura de Timor-Leste, o nosso compromisso é com uma experiência de pesquisa que se vincula a "processos formativos como projetos ontoculturais, bem como a projetos de possibilidades histórico-emancipacionistas" (MACEDO, 2016, p.94),

como uma modalidade de pesquisa que se nutre de forma radical da experiência narrada e seus etnométodos - daí seu viés etno - para instituir seus modos de criação de conhecimento e a especificidade do conhecimento que produz, a etnopesquisa que muito valoriza epistemológica, heurística e politicamente a experiência do próprio ato de pesquisar, se afasta dos padrões de inspiração positivista em ciências antropossociais e da educação em que a experiência é vista como epifenômeno, algo a ser descarte ou a ser reduzido por algum modelo explicativo para se transformar em um conjunto de "dados": sua coisificação. (MACEDO, 2015, p. 29).

Estas elaborações da etnopesquisa, diz Macedo, vêm da etnometodologia, teoria do social contextualista e acionalista, fundada por Harold Garfinkel (MACEDO, 2015, p. 29). Indexicalidade e reflexividade são dois dos principais conceitos desta teoria que destacamos no quadro acima para nos referir ao significado e importância da educação escolar ser produzida a partir do que vivem e dizem os seus atores no contexto de uma sociedade cuja existência se afirma pela existência da uma-lulik. A indexicalidade indica a contextualidade e a reflexividade refere-se à propriedade de o mundo se constituir pela linguagem, pelos sentidos e significados produzidos no contexto. Assim, o trabalho de descrever, narrar, relatar práticas e experiências relacionadas à uma-lulik dos seus atores será constitutivo da educação escolar indexicalizada, produzida de modo inter-relacionado também com as demais atividades e cosmologia da uma-lulik, o contrário do que acontece num projeto e modelo de currículo e de escola em que as experiências e saberes dos atores não encontram espaço, são silenciados e negados, porque o que é tido como válido é somente o que é produzido pelas epistemologias do Norte.

Então, olhar a uma-lulik como "um modo de vida inteiro" é poder concebê-la como uma referência fundante e ter uma visão que supera a sua redução a folclore ou até mesmo à 
Rev. Interd. em Cult. e Soc. (RICS), São Luís, v. 7, n. 1, p. 108- 126, jan./jun. 2021

ISSN eletrônico: 2447-6498

alma da nação mas num sentido idílico apenas, como observou Sousa (2009), ao não se vê a mesma valorização, reconhecimento e afirmação da alma de Timor na organização da vida social pelo Estado, em termos da produção material e simbólica - que é relacional - da economia, política, saúde, educação, etc.

An idyllic level, the mountains, their inhabitants, and the ancestors are considered the souls of the country. Adat is praised as the "soul" of the nation/used in reconciliation processes/ecological benefits (tara bandu) and used as national "folklore", namely in the reception of foreign dignitaries. (SOUSA, 2009, p. 109).

É por aí que pensamos que no campo da educação escolar (do currículo, da formação), a uma-lulik pode ter um lugar e um papel muito maior, agindo nos seus fundamentos, objetivos e organização. De acordo com Sousa (2009),

the roots of the people linked them to a territory and its people: their ancestors, their kinsmen and allies "desde uluk kedas" - since the beginning of time. Roots in this sense are territorial markers but also metaphors of life and life vitality (of the individual, the House and the community). Maintaining the roots of people is much more than the mere vision of adat as a tradition to use in public State/Church displays. Adat as roots is essential for relating land and people, their history and present, to maintain land and life, and from the local insight to sustain the nation. (SOUSA, 2009, pp. 111112)

A esse respeito, importante também nos parece trazer aqui, e levamos bastante em consideração, a observação de Paulino (2014) de que os processos de colonização produziram uma visão das estruturas sociais e das culturas dos povos colonizados como sendo "grotescas imitações ou réplicas imperfeitas das estruturas da cultura europeia" e de que "terá que existir algo que faz com que uma sociedade (quer a sociedade tradicional quer a sociedade póstradicional) valorize a sua etnicidade diferenciada" (PAULINO, 2014, p. 11). Os processos de colonização continuam produzindo seus frutos e esta visão ainda está muito longe de desaparecer do imaginário das instituições produzidas pela modernidade - ainda que muitas vezes seus atores dele não tenham qualquer consciência - que é constitutivo do modo de vida capitalista, que se tornou global.

Paulino (2012) afirma que "a civilização timorense está ligada às uma-lulik (casas sagradas) e aos cultos dos lulik (sagrado). Nas práticas rituais, as casas sagradas se ligam normalmente à origem de vida e à relação da vida social do ser humano". E, mais, como também reconhecem McWilliam, Palmer e Shepherd (2014), “o lulik permanece amplamente a ordem filosófica, religiosa, moral e epistêmica que guia as relações entre os timorenses, sendo assim um ator poderoso na formação de ideias, conversações e práticas em todo 
Rev. Interd. em Cult. e Soc. (RICS), São Luís, v. 7, n. 1, p. 108- 126, jan./jun. 2021

ISSN eletrônico: 2447-6498

compartilhamento intercultural $^{17}(2014$, p. 318). Nós reconhecemos a complexidade que envolve a investigação deste contexto bem como reconhecemos a necessidade de olhá-lo, escutá-lo mais profundamente ${ }^{18}$ para poder dele aproximar mais a educação escolar, suas políticas e práticas de currículo e formação.

Vemo-nos no modo de vida capitalista neoliberal separados do que somos e do mundo ao nosso redor, vemos a realidade em fragmentos. Distanciamo-nos, a nosso ver, da riqueza do existir. O que é esse existir? Qual é a natureza de nossa existência? A investigação do diálogo possível entre a escola e a uma-lulik intenciona olhar para o colo, ver o que está no ventre/interior/âmago/íntimo da existência no contexto da sociedade timorense, que cultiva uma forte ligação com a natureza e com os antepassados. Então, almejamos este encontro da escola com a uma-lulik, que é constitutiva e se constitui da lisan. Neste sentido, destacamos aqui mais um sentido de lisan apresentado por Paulino (2012):

Podemos verificar que a expressão lisan é constituída por duas sílabas, lí e san - lí significa ver ou observar, e san tem origem no verbo substantivado sau, que em português equivale ao verbo trazer ao colo ou trazer no ventre. É um termo que tem o mesmo significado da palavra cultura, proveniente do verbo colo, que no Latim significa "eu cultivo", especificamente, "eu cultivo o solo". Isto é, tanto a lisan como a cultura seriam, basicamente, o campo a ser cultivado, para quem vai trabalhar a terra. (PAULINO, 2012, p. 54).

A ligação com a terra é central no conceito de lisan que Paulino descreve relacionando-o ao termo cultura. Observando a composição do termo lisan, ficamos pensando no que é a língua. A palavra contém o que é sentido, sofrido, pensado, vivido por quem a diz na sua origem e é internalizada naqueles que passam a dizê-la, traduzindo o que sentem, sofrem, pensam, vivem, é o que nos lembra Lydia Hortélio ${ }^{19}$. É por isso que fazer desaparecer a língua e as experiências de um povo é também destruir a sua alma ancestral. Reconhecemos também o valor da tradução que permite o encontro, o acesso, 0 (re)conhecimento do outro.

A investigação do diálogo possível entre escola e uma-lulik requer uma compreensão do significado e importância da tradução intercultural e a assunção dela como procedimento de pesquisa, de acordo com o que propõem as epistemologias do Sul, mas não só a intercultural como também a tradução intracultural, dado que as experiências vividas pelos

\footnotetext{
${ }^{17}$ Tradução nossa.

${ }^{18}$ Santos escreve sobre a visão e a escuta profundas no capítulo 8 do livro "O fím do império cognitivo: a afirmação das epistemologias do Sul, onde discute a necessidade de o investigador pós-abissal aprender a ver, escutar, sentir profundamente para que seja capaz de transpor os limites de uma compreensão fechada na compreensão ocidental do mundo que é dominante nas nossas formações nas escolas, nos ambientes acadêmicos em geral.

${ }^{19}$ Live com Lydia Hortélio em 19/06/2020. www.sympla.com.br.
} 
Rev. Interd. em Cult. e Soc. (RICS), São Luís, v. 7, n. 1, p. 108- 126, jan./jun. 2021

ISSN eletrônico: 2447-6498

sujeitos num mesmo território, com uma cultura própria, também são reveladoras de uma heterogeneidade singular, o que buscamos alcançar também com o auxílio da abordagem auto-hetero-biográfica. "Quando um ator conta algo fala do mundo vivido, da sua experiência no mundo em que se socializa". Sempre contamos algo para alguém. A experiência de contar envolve uma dimensão subjetiva e uma dimensão objetiva. É por meio desta dinâmica relacional que construímos o saber. É assim que Delory-Momberger (2019) ${ }^{20}$ nos apresenta a noção da auto-heterobiografização.

À língua se juntam as outras práticas e experiências sociais, tradicionais, culturais que são criadas por um povo e são constitutivas de um território e só são possíveis de acessar em seus significados e sentidos por meio da descritibilidade, relatabilidade, da prática (da realização) de seus membros ${ }^{21}$, pelas suas propriedades indexicais e reflexivas.

\section{CONSIDERAÇÕES FINAIS}

Tendo em vista o caráter construcionista das etnopesquisas-formação, partimos de "um certo acionalismo propositivo" (MACEDO, 2017, p. 81) para pensar a questão da busca e operacionalização de diálogos possíveis entre escola e uma-lulik.

Temos a oportunidade e podemos olhar, reconhecer e valorizar experiências ancestrais que sofreram a violência, o silenciamento e a negação neste movimento "civilizatório", que na verdade foi/é colonizador e trabalha numa lógica de eliminação das diversas experiências no mundo, impondo um modelo único de vida para todos, o qual vem mostrando cada vez mais o quanto é perverso e destrutivo.

As abordagens, teorias, noções e conceitos aqui apresentados e articulados se revelam dispositivos para ações e realizações curriculares e formacionais culturalmente referenciadas capazes de operar no sentido de trazer para a educação escolar, de modo valorado, experiências que foram mesmo muito ridicularizadas pelos processos de modernização, quando não eliminadas, mas que têm alto valor formacional - sobretudo quando pensamos nos problemas do tempo presente que envolvem a relação do ser humano com a natureza, com os outros seres humanos, com sua própria natureza, com o princípio da vida e da existência, as

\footnotetext{
${ }^{20}$ Conferência com o tema "La recherche biographique ou la construction partagée d'un savoir du singulier", por Christine Momberger Delory-Momberger, no PPGEduC - Universidade do Estado da Bahia (UNEB), em 24/09/2019.

${ }^{21}$ Prática, relatabilidade/descritibilidade, indexicalidade, reflexividade, condição de membro são os conceitos básicos da etnometodologia (ver Garfinkel, 2018; Coulon, 1995, 2017; Macedo, 2000; Sousa, 2019).
} 
Rev. Interd. em Cult. e Soc. (RICS), São Luís, v. 7, n. 1, p. 108- 126, jan./jun. 2021

ISSN eletrônico: 2447-6498

relações entre natureza e cultura - e a condição de nos fazer questionar e tensionar o modo de vida dominante.

A experiência da uma-lulik sobre a qual nos debruçamos neste trabalho, fazendo entrever o significado do diálogo entre ela e a escola e sua potência pedagógica, cultural e política, a partir da abordagem etnoconstitutiva de currículo e formação.

Não desconhecemos ou negamos o universo misterioso do lulik, respeitamo-lo e sabemos que não podemos desconsiderar a necessidade do pedido de licença e da permissão para podermos nele entrar. Adentrar esta realidade passa por interesses e implicações pessoais, mas vai além na medida em que o que sustenta este propósito é o nosso compromisso com o cuidado, o respeito, a valorização, o fortalecimento e afirmação da vida.

Do lugar de comprometimento e luta em que nos situamos não podemos nos deixar vacilar e falhar na compreensão daquilo que o modelo de vida centrado no capital produz e em tudo o que ele faz desaparecer, como temos visto acontecer mesmo em territórios que resistiram e mantiveram práticas e sentidos primordiais de suas experiências ancestrais sofrendo as colonizações e imposições de outro modo de vida. Timor-Leste pode não estar muito longe de estar correndo este risco. É possível contribuir para um currículo e formação que (re)nasça do encontro com esta fonte, acreditamos. Além disso, estamos reconhecendo a urgência de pistas e alternativas para a vida na terra, no mundo. Timor-Leste, sobretudo na experiência da uma-lulik, tem muito a nos mostrar e ensinar.

\section{REFERÊNCIAS}

ANDERSEN, I. Foreword by the Executive Director of UNEP. In: Preventing the next pandemic: Zoonotic diseases and how to break the chain of transmission. Science Division United Nations Environment Programme. Kenya, 2020. Disponível em:

https://reliefweb.int/sites/reliefweb.int/files/resources/ZP.pdf. Acesso em 13 de julho de 2020.

AZEVEDO, F. P. O Conceito de cultura em Raymond Williams. Revista Interdisciplinar em Cultura e Sociedade (RICS). São Luís, vol. 3, nº especial, 2017.

BARROS, J. Casa Turi-Sai: um tipo de casa timorense. Revista da Junta de Investigações do Ultramar, Garcia de Orla, Série de Antropologia, vol. 2, nº 1 e 2, Lisboa, 1975.

BOFF, L. Adoecemos a Terra e a Terra nos adoece. Ecologia dos Saberes. Disponível em: https://educezimbra.wordpress.com/2017/10/28/adoecemos-a-terra-e-a-terra-nos-adoece/. Acesso em 17 de abril de 2020.

COULON, A. Etnometodologia e Educação. Trad.: Ana Teixeira. São Paulo: Cortez, 2017. A. Etnometodologia. Petrópolis-RJ, Editora Vozes, 1995. 
Rev. Interd. em Cult. e Soc. (RICS), São Luís, v. 7, n. 1, p. 108- 126, jan./jun. 2021 ISSN eletrônico: 2447-6498

MACEDO, R. S. Currículo: campo, conceito e pesquisa. $7^{\text {a }}$ edição. Petrópolis, RJ, Vozes, 2017.

A teoria etnoconstitutiva de currículo: teoria-ação e sistema curricular formacional. Curitiba, CRV, 2016.

; MACEDO DE SÁ, S. M. Etnocurrículo, Etnoaprendizagens: a educação referenciada na cultura. São Paulo, Edições Loyola, 2015.

A etnopesquisa implicada: pertencimento, criação de saberes e afirmação. Brasília, Liber Livro Editora, 2012.

. Etnopesquisa crítica, etnopesquisa-formação. Brasília, Liber Livro Editora, 2006.

. A etnopesquisa crítica e multirreferencial nas ciências humanas e na educação.

Salvador, EDUFBA, 2000.

MCWILLIAM, A.; PALMER, L.; SHEPHERD, C. Lulik encounters and cultural frictions in East Timor: Past and present. The Australian Journal of Anthropology, 25, 2014.

Disponível em: https://onlinelibrary.wiley.com/doi/epdf/10.1111/taja.12101. Acesso em 13 de abril de 2020.

PAUlinO, V. A composição multiétnica de Timor-Leste. Dili, TL: Revista Veritas, v. 2, $\mathrm{n}^{\mathrm{o}} 3,2014$.

PAULINO, V. Representação identitária em Timor-Leste: culturas e os mídia. 2012. Tese (Doutorado em Ciências da Cultura) Faculdade de Letras, Universidade de Lisboa, Lisboa, 2012.

SANTOS, B. S.; MENESES, M. P. (orgs.). Epistemologias do Sul. São Paulo: Cortez, 2010.

O fim do império cognitivo: a afirmação das epistemologias do Sul. Belo Horizonte, Autêntica, 2019.

. "Desafios da pandemia para a sociedade, para a ciência e para o CES. Ciclo de

Seminários online: Conversas Desconfinadas". Centro de Estudos Sociais, Universidade de Coimbra, 9 de junho de 2020. Disponível em https://youtu.be/HzNZg9DP010. Acesso em 17 de junho de 2020 .

SHIVA, Vandana. Um vírus, a humanidade e a terra. Revista IHU on-line: Diálogo interconvicções. Instituto Humanitas Unisino. http://www.ihu.unisinos.br/598043- Acesso em 15 de abril de 2020.

SOUSA, L. Denying peripheral status, claiming a role in the nation: sacred words and ritual practices as legitimating identity of a local community in the context of the new nation. 2009. 10.4000/books.irasec.665. Disponível em https://www.researchgate.net/publication/260105803. Acesso em: 15 de maio de 2020. 
Rev. Interd. em Cult. e Soc. (RICS), São Luís, v. 7, n. 1, p. 108- 126, jan./jun. 2021 ISSN eletrônico: 2447-6498

SOUSA, R. C. Observatório Etnoformador em Timor-Leste: uma tecnologia de formação por outro ethos pedagógico escolar/institucional. 2019. Dissertação (Mestrado em Educação Científica e Tecnológica). Universidade Federal de Santa Catariana, Florianópolis, 2019. 